\title{
Discovery of the Class I Antimicrobial Lasso Peptide Arcumycin
}

\author{
Lydia M. Stariha and Dewey G. McCafferty*
}

Department of Chemistry

Duke University

Durham, NC, 27708-0346 (USA)

E-mail: dewey.mccafferty@duke.edu

Supporting information for this article is given via a link at the end of the document.

\begin{abstract}
Lasso peptides are a structurally diverse superfamily of conformationally-constrained peptide natural products, of which a subset exhibits broad antimicrobial activity. Although advances in bioinformatics have increased our knowledge of strains harboring the biosynthetic machinery for lasso peptide production, relating peptide sequence to bioactivity remains a continuous challenge. Towards this end, a structure-driven genome mining investigation of Actinobacteria-produced antimicrobial lasso peptides was performed to correlate predicted primary structure with antibiotic activity. Bioinformatic evaluation revealed eight putative novel class I lasso peptide sequences. This subset is predicted to possess antibiotic activity as characterized members of this class have both broad spectrum and potent activity against Grampositive strains. Fermentation of one of these hits, Streptomyces NRRL F-5639, resulted in the production of a novel class I lasso peptide, arcumycin, named for the Latin word for bow or arch, arcum. Arcumycin exhibited antibiotic activity against Grampositive bacteria including Bacillus subtilis (4 $\mu \mathrm{g} / \mathrm{mL})$, Staphylococcus aureus $(8 \mu \mathrm{g} / \mathrm{mL})$, and Micrococcus luteus (8 $\mu \mathrm{g} / \mathrm{mL}$ ). Arcumycin treatment of $B$. subtilis lial- $\beta$-gal promoter fusion reporter strain resulted in upregulation of the system liaRS by the promoter lial, indicating arcumycin interferes with lipid II biosynthesis. Cumulatively, the results illustrate the relationship between phylogenetically related lasso peptides and their bioactivity as validated through the isolation, structural determination, and evaluation of bioactivity of the novel class I antimicrobial lasso peptide arcumycin.
\end{abstract}

\section{Introduction}

The discovery of antibiotics revolutionized the treatment of infectious disease. However, over the past thirty years, the rate of introduction of new-in-class antibiotics has flattened, yet the simultaneous rate of clinical cases of infections due to bacteria that are resistant to front-line antibiotics has steadily increased. Given our dwindling arsenal of effective antibiotics, it is not difficult to see a time when our most serious infectious threats may be untreatable. ${ }^{[1]}$ In the United States alone, there are 2.8 million reported cases and 35,000 deaths annually due to resistant bacterial infections. ${ }^{[2]}$ Natural products have proven to be critical sources for antibiotics, as over $70 \%$ of clinically approved treatments are natural products or natural product derivatives. ${ }^{[3]}$ Bioinformatic analyses have estimated there are thousands of predicted compounds with novel structures and biological activities that are yet to be discovered and functionally validated. ${ }^{[4]}$

Lasso peptides are a superfamily of ribosomally synthesized and post-translationally modified peptide natural products (RiPPs). ${ }^{[5]}$ First discovered in the 1990 s, lasso peptides are produced by numerous bacterial species, including members of the Proteobacteria, Actinobacteria, and Firmicutes phyla. ${ }^{[6],[7]}$ These peptides have a wide range of bioactivities including antiviral, ${ }^{[8]}$ anticancer, ${ }^{[9]}$ cell-surface receptor agonist, ${ }^{[10]}$ and antimicrobial. ${ }^{[11-15]}$ To date, there are over 80 characterized lasso peptides. Each shares a general structure comprised of 16-25 amino acids that are characterized by an intramolecular macrocycle through which is threaded a C-terminal tail region to create a knot structure. Adoption of its unusual lariat-like topology is essential for bioactivity, ${ }^{[16][17]}$ renders the lasso peptide thermostable ${ }^{[18]}$ and protects the peptide backbone against proteolytic degradation. ${ }^{[19]}$

Within the superfamily, a subset of peptides also contains intramolecular disulfide bonds that increase stability. Four structural classes of lasso peptides have been classified based in part on the number and location of the disulfide bonds (Figure 1). ${ }^{[20]}$ Class I members are characterized by two disulfide bonds between residues Cys $_{1}$-Cys 13 and Cys $_{7}-$ Cys $_{19}$, (e.g. siamycin I) (Figure 1). Class II members lack disulfides (e.g. propeptin), while class III and IV peptides contain a single disulfide with class III between residues $\mathrm{Cys}_{7}-\mathrm{Cys}_{20}$ (e.g. BI-32169), and class IV between Cys $_{13}$-Cys 17 (e.g. LP-2006). Within each class, members exhibit some diversity of amino acid sequence, ${ }^{[21],[22]}$ peptide length, ${ }^{[23],[24]}$ macrocycle size, ${ }^{[25]}$ post-translational modification, ${ }^{[26],[27]}$ and residues involved in macrocyclization. ${ }^{[28]}$

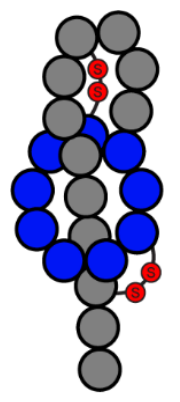

class I

siamycin I

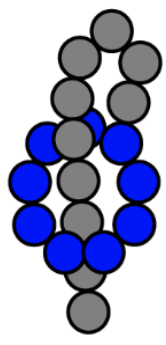

class II propeptin

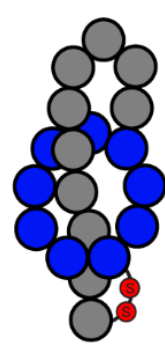

class III

BI-32169

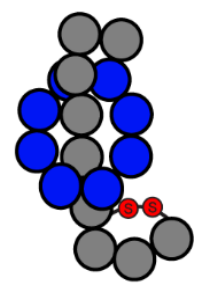

class IV
Figure 1. Representative structures of the four lasso peptide classes. Blue residues denote amino acids within macrocycle regions, grey residues belong to tail regions, and red indicates disulfide bonds.

Advances in genome mining have accelerated the study of lasso peptides by vastly expanding our knowledge of strains containing the biosynthetic machinery to produce this class of natural products. ${ }^{[29-31]}$ Sequence comparison algorithms such as RODEO, developed by Mitchell and coworkers, ${ }^{[31]}$ and decRiPPter, developed by Medema and colleagues, ${ }^{[32]}$ have significantly advanced the discovery of RiPP biosynthetic gene clusters (BGCs) within bacterial genomes. Genome mining studies of lasso peptides have been used to explore novel producers like the fungal-associated bacterium Rhizopua microspores ${ }^{[33]}$ and to discover unique post-translational modifications such as acylation. ${ }^{[34]}$ While genome mining has expanded the known chemical space of lasso peptides, relating structure to bioactivity has remained a challenge with fewer than 30 of the 80 characterized lasso peptides having reported activity. ${ }^{[35]}$ 
A)

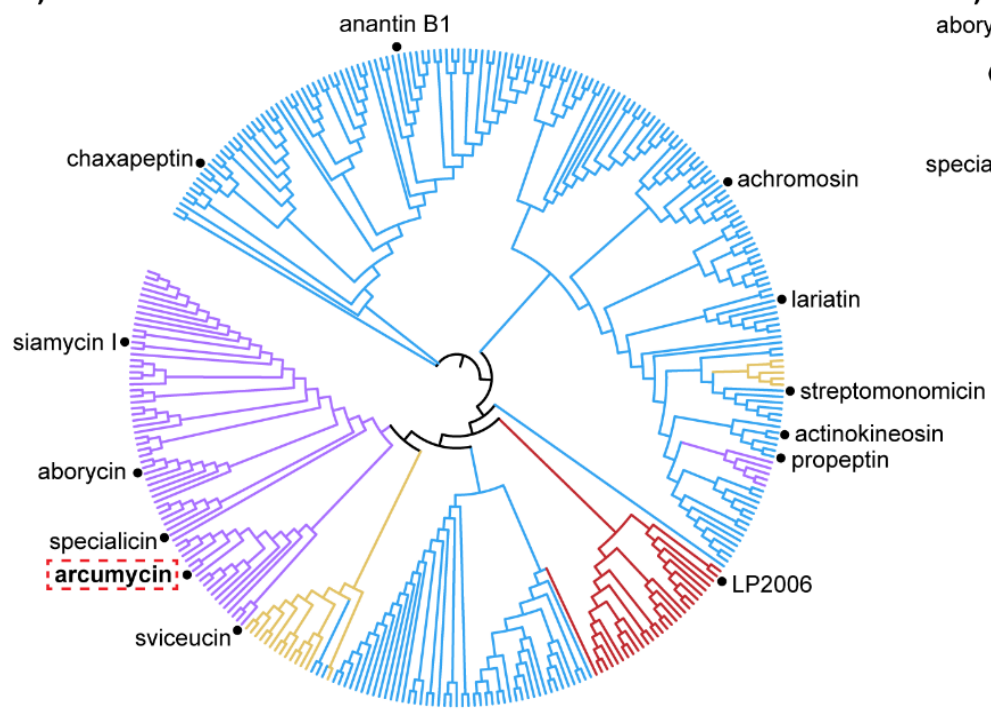

${ }^{\circ}$ Class I ${ }^{\circ}$ Class II ${ }^{\circ}$ Class III $\bullet_{\text {Class IV }}$
B)

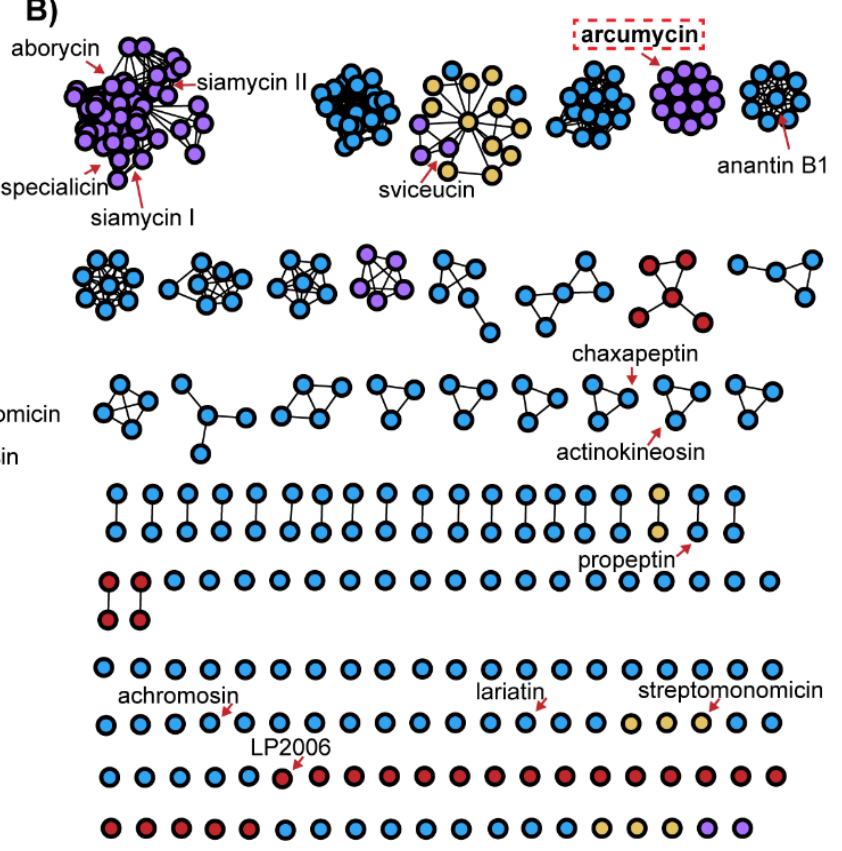

Figure 2. Phylogenetic analyses of predicted antimicrobial lasso peptides from Actinobacteria. (A) The multi-locus maximum-likelihood phylogenetic tree was generated from 331 BGCs from unique strains using CORASON. (B) Sequence similarity network of the 331 lasso peptide BGCs generated by BiG-SCAPE.

\section{Results and Discussion}

We hypothesized that lasso peptides identified in strains that are phylogenetically related to known antimicrobial lasso peptides producing strains may result in the discovery of novel lasso peptides with conserved structural features resulting in similiar bioactivities. As such, we designed a focused, structure-driven genome mining study to identify lasso peptide BGCs that are related to lasso peptides with well-established antimicrobial activity. We analyzed known antimicrobial lasso peptides produced by Actinobacteria to expand the chemical space surrounding these natural products. There are currently fifteen lasso peptides produced by Actinobacteria that have reported antimicrobial activity, and twelve have completely annotated BGCs available on the NCBI database (Table S1). ${ }^{[7],[26],[31],[36-44]}$ By studying biosynthetic diversity within this one phylum, the genetic diversity of the input data is lowered, allowing for the identification of more discrete variations within $B G C$ sequences and phylogenetic relationships.

Lasso peptide biosynthesis requires four proteins for production and maturation of the natural product: 1) the precursor peptide, comprised of the leader peptide that is recognized by tailoring proteins and the core peptide that contains the primary amino acid sequence of the mature natural product; 2) a lasso cyclase, which forms the isopeptide macrocyclic bond within the core peptide; 3 ) the RiPP recognition element, which binds to the leader peptide; and 4) the leader peptidase, which cleaves the leader peptide from the core peptide. ${ }^{[45],[46]}$ To explore structural diversity directly related to lasso peptide sequence, we elected to use the precursor peptide from each of the twelve characterized antimicrobial lasso peptides as queries in alignment searches. We conducted BLASTp ${ }^{[47]}$ searches against the NCBI database for each of the precursor peptides, and all resulting sequences query were collected as preliminary hits. Our hits were dereplicated across the different search queries and the surrounding biosynthetic machinery for lasso peptide biosynthesis was detected using antiSMASH 5.0. ${ }^{[48]}$

A total of 331 unique strains harboring the machinery for lasso peptide biosynthesis were identified, with several containing two different precursor peptides within the same cluster, providing a total of 345 predicted core peptide sequences (Dataset 1). Most of these BGCs were found among Streptomyces, but 39 genera and over 250 unique species were also predicted to harbor BGCs for lasso peptide biosynthesis. Interestingly, we detected four previously characterized lasso peptides that have either not been tested for antimicrobial activity (Res-701-3, ulleungdin, humidimycin) or were tested for antimicrobial activity against only a small number of strains (cattlecin), potentially indicating undiscovered antibiotic bioactivities. ${ }^{[9],[49-51]}$ Among the 345 predicted lasso peptide sequences identified, we observed representation of each structural class as determined by the location and number of predicted disulfide bonds (70 class I, 217 class II, 27 class III, 31 class IV). The hits from our genome mining efforts were further analyzed through the use of bioinformatic tools allowing for the evaluation of sequence relationships based on evolutionary proximity.

To complement the traditional division of lasso peptides into classes based on disulfide bonds, we sought to use evolutionary proximity to evaluate the relationships of antimicrobial lasso peptides. To determine the phylogenetic relationships and sequence similarity for all lasso peptide BGCs within each unique strain, CORASON and BiG-SCAPE were employed, respectively. ${ }^{[52]}$ While the data output for the phylogenetic tree and sequence similarity network (SSN) contains many similarities, using both of these tools facilitated the tracing of evolutionary proximity and relationships between BGC sequences. As CORASON and BiG-SCAPE perform multi-locus analyses for an entire BGC instead of a singular protein, these bioinformatic methods are particularly advantageous for lasso peptides that generally have smaller BGCs and lower molecular weight biosynthetic proteins. The lasso cyclase was used as the query for CORASON as it retains high homology across all input strains and is at the center of the BGC, allowing for the complete comparison of all strains and full clusters. Using this analysis, a multi-locus unrooted phylogenetic maximum-likelihood tree was generated tracing the evolutionary relationships for our 331 lasso peptide BGCs (Figure 2A). Lasso peptide classes form separate clades within the phylogenetic tree while previously characterized antimicrobial peptides are distributed throughout the clades and share lineages with other putative peptides within their class. Consistent with this result, the BGC SSN generated by BiG- 

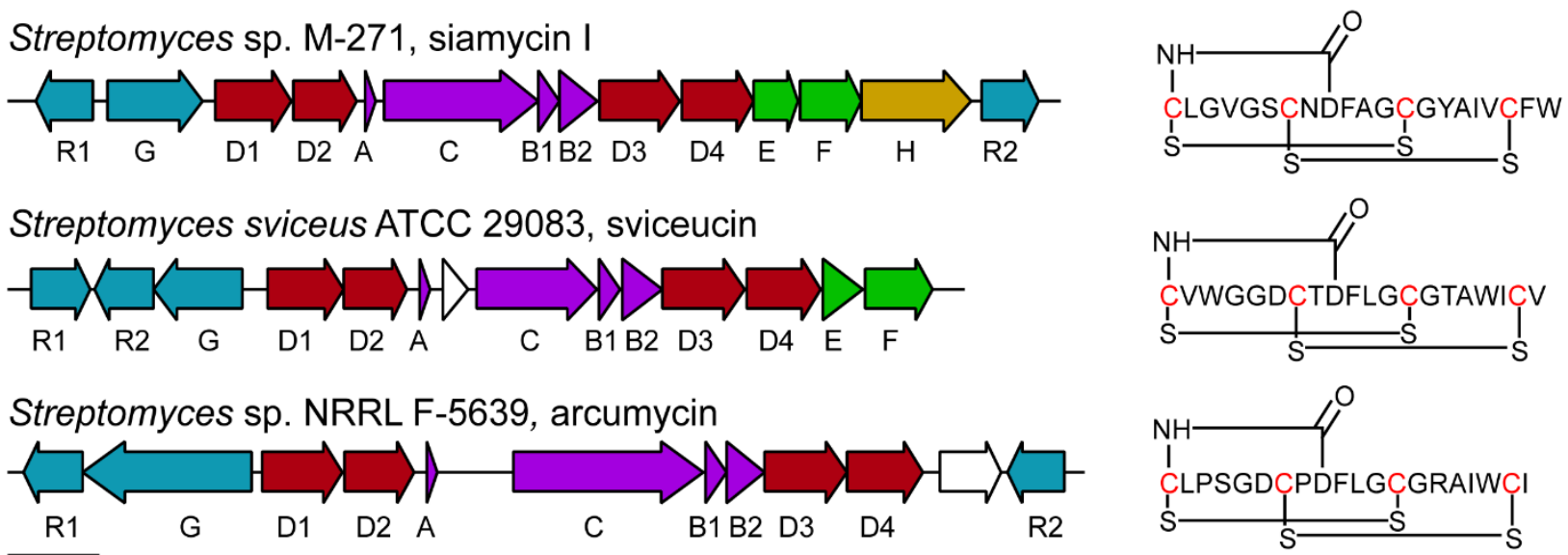

$1 \mathrm{~kb}$

transportation

biosynthesis

thiol-disulfide

epimerase

unknown function

Figure 3. Biosynthetic and structural comparison of class one lasso peptides. Open reading frame arrow diagrams and amino acid sequences of class I lasso peptide natural products including previously characterized structures and putative novel member arcumycin.

SCAPE indicates predominant clustering of nodes based on structural class (Figure 2B).

While the structural class II lasso peptides, which are devoid of disulfide linkages, represent the majority of identified sequences at $61 \%$, the disulfide-containing lasso peptides (classes I, III, and IV) are more highly represented in our results compared to previous genome mining studies. ${ }^{[31]}$ This result illustrates the vast chemical space for disulfide bond-containing lasso peptides that is yet to be explored. This is significant as lasso peptides with disulfide bonds have been demonstrated to display interesting bioactivities. Generally, class I lasso peptides have shown broad-spectrum and potent antimicrobial activity. As an example, siamycin I, the most widely studied of the disulfide bond-containing lasso peptides, has been shown to bind cell wall biosynthesis intermediate lipid $I I,{ }^{[53]}$ inhibit the futalosine pathway, ${ }^{[54]}$ and attenuate quorum sensing in Enterococcus faecalis. ${ }^{[5]}$ Within the siamycin I clade, we identified several novel putative class I lasso peptides, providing naturally-produced congeners of this antimicrobial lasso peptide to explore for antimicrobial activity.

As several of the putative class I lasso peptide BGCs presented novel arrangements, we sought to interrogate which enzymatic features were conserved and which were not broadly required for lasso peptide production. To compare the BGCs encoding class I lasso peptides, we first removed BGCs containing redundant precursor peptides to specifically investigate variations in natural product primary sequence, resulting in 22 unique BGCs (SI Table 2). We then determined the composition of each BGC, which revealed four distinct archetypes based on putative enzymes present in the BGC: siamycin, sviceucin, novel BGCl, and novel BGCII (SI Figure 1). In comparing the sequences of the proteins encoded in these BGCs to that of siamycin I, it was illustrated that the core biosynthesis genes have a high level of homology, especially for the precursor peptide (SI Table 3). Additionally, the flanking four $\mathrm{ABC}$ transporter proteins retained high levels of sequence similarity, indicating a conserved mechanism for selfresistance ${ }^{[56]}$ All BGCs within the siamycin family encoded the hypothetical epimerase for the conversion of the terminal tryptophan residue to the D-Trp conformation, but this putative gene was not present in the other archetypes. BGCs belonging to both the siamycin and sviceucin-type BGCs contain two thioldisulfide oxidoreductases, a protein found only in BGCs for class I lasso peptides. These proteins have been previously investigated for their role in the biosynthesis of class I lasso peptides, with in-frame deletions of these genes resulting in lower production of the final natural product, but not full elimination of production or loss of disulfide bond formation. ${ }^{[38],[57]}$ Interestingly, the archetypes of novel $\mathrm{BGCl}$ and novel BGCII from our analysis do not contain any putative thiol-disulfide oxidoreductases, indicating these genes may not be essential for full maturation. To determine if alterations in BGC composition affect the production of class I lasso peptides or have any relationship to the bioactivity of the natural products, we selected to isolate a novel lasso peptide from BGCII.

To validate the predictions made through our analysis of class I lasso peptides produced by Actinobacteria, we elected to isolate, verify the structure, and determine the bioactivity of a new class I lasso peptide. The bacterial strain Streptomyces NRRL F-5639, identified as harboring a BGC encoding a unique lasso peptide, was obtained from the Agricultural Research Service Culture Collection. This strain was selected as the BGC belongs to the previously uncharacterized archetype BGCII, containing the four core genes for lasso peptide biosynthesis, four $A B C$ transporter proteins, and three genes for transcriptional regulation. Putative epimerases and thiol-disulfide oxidoreductases are absent from this cluster (Figure 3). Using antiSMASH with the RODEO extension, ${ }^{[31]}$ this novel class I lasso peptide-that we have named arcumycin after the Latin word for bow or arch-was predicted to be 20 amino acids in length with a macrocycle of nine amino acids cyclized between Cys $1-\mathrm{Asp}_{9}$ and two disulfide bridges between $\mathrm{Cys}_{1} \mathrm{Cys}_{13}$ and $\mathrm{Cys}_{7}-\mathrm{Cys}_{19}$ (Figure 3). The peptide sequence of arcumycin was determined to have an overall amino acid identity to both the siamycin family and sviceucin of $55 \%$, classifying this peptide as a novel subfamily of the class I lasso peptides while still having the potential to retain key structural elements for bioactivity. ${ }^{[38],[58]}$

To determine if the BGC for arcumycin could be activated, we first screened for peptide production from Streptomyces NRRL F5639 using media conditions that have been used to produce other class I lasso peptides. ${ }^{[40],[38],[54],[55]}$ None of the conditions resulted in the production of the novel lasso peptide as detected by MALDI-MS. We next screened numerous liquid media formulations optimized for Actinomycete metabolome profiling, ${ }^{[59]}$ and arcumycin was found to be produced in seven of these conditions with the predicted mass detected by MALDI-MS and ESI-MS (SI Figure 2). We selected RAM media in our scale-up conditions as it showed the highest concentration of peptide (SI Figure 3). Guided by lasso peptide structural prediction tools, we experimentally validated the structure of arcumycin. We observed a $[\mathrm{M}+2 \mathrm{H}]^{2+}$ of $1052.4519 \mathrm{~m} / \mathrm{z}$ by high-resolution LC-MS, confirming the predicted chemical formula of $\mathrm{C}_{92} \mathrm{H}_{134} \mathrm{~N}_{24} \mathrm{O}_{25} \mathrm{~S}_{4}$ (calculated $[\mathrm{M}+2 \mathrm{H}]^{2+}$ 1052.4490). We next sought to determine connectivity by MS/MS. Typically, only the tail regions of lasso peptides have been elucidated with MS/MS analysis due to the stability of the macrolactam, which leads to

poor levels of fragmentation within the macrocyclic region. However, recent advancements using higher-energy C-trap dissociation (HCD) over collisional-induced dissociation (CID) have resulted in complete connectivity validation for some peptides. ${ }^{\left[{ }^{[0]}\right]}$ We performed an HCD-MS/MS analysis on a reduced 

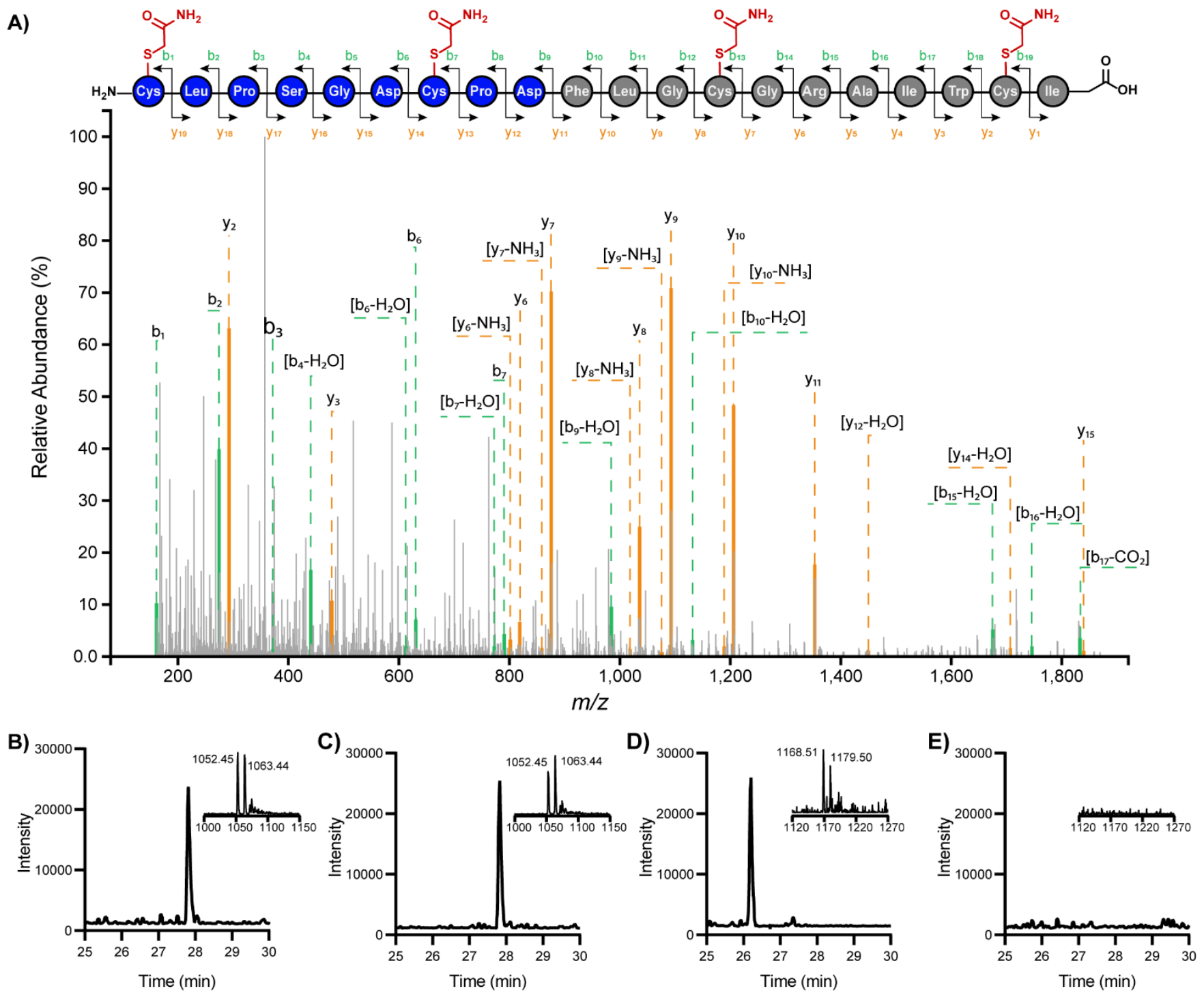

Figure 4. Mass spectral verification of arcumycin sequence and topology. (A) MS/MS spectrum of reduced and alkylated arcumycin (macrocycle blue, tail grey, alkylated sulfurs red) with diagnostic fragmentation pattern b- (green) and y-ions (yellow). Extraction ion chromatograms and mass spectra of (B) arcumycin $\left([\mathrm{M}+2 \mathrm{H}]^{2+}=1052.4490\right),(\mathrm{C})$ arcumycin exposed to carboxypeptidase $\mathrm{Y}\left([\mathrm{M}+2 \mathrm{H}]^{2+}=1052.4490\right),(\mathrm{D})$ reduced and alkylated arcumycin $\left([\mathrm{M}+2 \mathrm{H}]^{2+}=1168.5077\right),(\mathrm{E})$ reduced and alkylated arcumycin after treatment with carboxypeptidase $\mathrm{Y}\left([\mathrm{M}+2 \mathrm{H}]^{2+}=1168.5077\right)$.

and alkylated arcumycin and the data was analyzed through the Interactive Peptide Spectral Annotator. ${ }^{[61]}$ The HCD-MS/MS analysis generated the corresponding $b$ - and $y$-ions to confirm the lasso peptide amino acid sequence for the linear peptide that would arise from a ring opening at the site of macrocyclization between Cys $_{1}$-Aspg (Figure 4A, SI Table 4). We further examined other possible ring opening sites for the macrocycle and found prominent fragmentation for cycle opening between Cys $1-\mathrm{Asp}_{9}$ and Leu2-Pro3 for the corresponding nine amino acid linear peptide of the macrocycle (SI Figures 4 and 5 , SI Tables 5 and 6). Collectively, the HCD-MS/MS data allowed for the validation of the amino acid sequence and connectivity of arcumycin. Additionally, we aimed to confirm the topology of the lasso peptide fold. Previous studies of lasso peptides have shown that fully maturated lasso peptides have resistance to proteolytic degradation, yet when unfolded to a branched linear form the natural product is vulnerable to proteases. ${ }^{[38],[62]}$ Analysis by LCMS showed that arcumycin was resistant to degradation by protease carboxypeptidase $Y$ in its native form; however, after disrupting this secondary structure through chemical reduction and alkylation of the disulfide bonds the peptide was degraded, which suggests that it adopts a lariat fold (Figure 4B, SI Figures 6-13).
Using broth microdilution assays, we evaluated the ability of arcumycin to inhibit the growth of bacteria. As arcumycin shares high levels of sequence similarity to both the siamycins and sviceucin, establishing its killing profile is an interesting way to increase the knowledge of how the structures of class I lasso peptides contribute to biological activity. We tested arcumycin against the four Gram-positive strains Bacillus subtilis ATCC 6051, Staphylococcus aureus ATCC 25923, Enterococcus faecalis ATCC 29212, and Micrococcus luteus ATCC 4698, and one representative Gram-negative strain Escherichia coli ATCC 25922. Our results show that arcumycin was not active against the Gram-negative bacterium, but induced inhibition against multiple Gram-positive bacteria at a concentration of $4-8 \mu \mathrm{g} / \mathrm{mL}$ similar to other class I lasso peptides (Figure 5A). This indicates that although arcumycin is not identical in sequence to other class I lasso peptides, it does retain important structural features for bioactivity. Interestingly, the class I lasso peptides exhibit high variability in the strains each peptide is active against. Arcumycin showed no activity against $E$. faecalis, but both siamycin I and sviceucin are active against this strain. The evaluation of bioactivity shows that, through SAR-driven genome mining, we are able to use the phylogenetic relationships of antimicrobial lasso peptides to discover a new member of class I with antimicrobial bioactivity. 
To further pursue the hypothesis that phylogenetically related lasso peptides will have similar bioactivities, we performed investigations into the mechanism of action of arcumycin. Previous studies have shown that seven Proteobacteriaproduced lasso peptides exhibit a similar mechanism of action that induces bactericidal activity via inhibition of RNA polymerase. ${ }^{[14]}$ While a similar conserved mechanism among Actinobacteria-produced lasso peptides has not been validated, initial evidence has shown that both siamycin [[53] and streptomonomicin $^{[63]}$ have similar resistance mutants, both within genes associated with cell wall biosynthesis. Further, siamycin I has been fully validated as a lipid II binder. ${ }^{[53]}$ To evaluate the ability of arcumycin to act as an inhibitor of cell wall biosynthesis, we employed a reporter assay using a $B$. subtilis strain harboring a lial- $\beta$-gal promoter fusion, which relies on the upregulation of the two component system liaRS by the promoter lial when cell wall envelope is under stress. ${ }^{[64]}$ When the fused lial- $\beta$-gal promoter is induced $\beta$-galactosidase is expressed and able to cleave the $X$-gal dye resulting in the formation of a blue-colored product. Treatment of the $B$. subtilis reporter strain with arcumycin produced a blue ring around the zone of inhibition, similiar to the known lipid II binder vancomycin (Figure 5B). While further analysis of the association of lipid II with arcumycin will help elucidate the molecular details of this interaction, these initial results suggest a shared mechanism of action may exist among structurally diverse Actinobacteria-produced lasso peptides. A)

\begin{tabular}{lc}
\hline Strain Name & MIC $(\mu \mathrm{g} / \mathrm{mL})$ \\
\hline Bacillus subtilis ATCC 6051 & 4 \\
Staphylococcus aureus ATCC 25923 & 8 \\
Micrococcus luteus ATCC 4698 & 8 \\
Enterococcus faecalis ATCC 29212 & $>32$ \\
Escherichia coli ATCC 25922 & $>32$ \\
\hline
\end{tabular}

B)

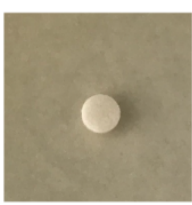

$\mathrm{MeOH}$

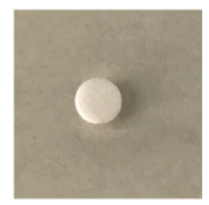

Kanamycin

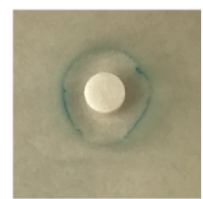

Vancomycin

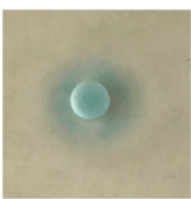

Arcumycin
Figure 5. Antimicrobial activity of arcumycin. (A) MIC values of arcumycin against select microbial strains. (B) Activation of transcriptional lial reporter in $B$. subtilis induced by treatment with arcumycin and positive control vancomycin.

\section{Conclusion}

In summary, through bioinformatic analyses of antimicrobial lasso peptides from Actinobacteria, we have demonstrated the potential of these techniques to relate lasso peptide sequence to antibiotic bioactivity. Analysis of the phylogenetic relationships of lasso peptides also illustrated a close relationship between genetic sequence and the previously described structure-based classification system. Using bioinformatics we identified several putative class I lasso peptides that were predicted to possess antimicrobial activity. Fermentation of the representative Streptomyces sp. NRRL F-5639 strain hit resulted in the production of a novel class I lasso peptide, arcumycin, which was structurally characterized and subsequently shown to possess antimicrobial activity against several Gram-positive bacterial test strains. Mode of action studies suggested that arcumycin interferes with lipid II biosynthesis, a mode of action shared with the class I lasso peptide siamycin I. ${ }^{[53]}$ Together, these studies may help inform the bioinformatics-guided discovery of new lasso peptides with biological activities.

\section{Experimental Section}

\section{General methods and materials}

Bacterial media components were obtained from Affymetrix, Fisher Scientific, Millipore-Sigma, and BD Difco Laboratories. A sample of Pharmamedia was obtained from Archer Daniels Midland Company, and fish meal was purchased from Coyote Creek Organic Feed Mill and Farm. Tomato paste, oatmeal, cornmeal, V8 juice, whole wheat flour, millet flour, and nutritional yeast were purchased from Harris Teeter. All chemical solvents and reagents were purchased through Millipore-Sigma with no further purification. Preparative and analytical reverse-phase HPLC purifications were performed on a Waters Prep 150B system with a Phenomenex octadecyl silica (C18) column (250 mm x $21 \mathrm{~mm}, 10 \mu \mathrm{m}, 300$ $\AA$ ) or Phenomenex C18 column $(250 \times 4.6 \mathrm{~mm}, 5 \mu \mathrm{m}, 300 \AA)$. Mass spectrometry analyses were collected on the following instruments: tandem MS/MS spectrometry was performed using Fusion Lumos Orbitrap mass spectrometer, matrix-assisted laser desorption time-of-flight mass spectrometry (MALDI-TOF) was performed using a Bruker Autoflex Speed LRF MALDI-TOF System, LC-MS analysis was done on an Agilent 6460 Triple Quadrupole system, and HR-MS spectra were collected on an Agilent 6224 LC/MS-TOF instrument.

\section{Bioinformatics}

The full biosynthetic gene loci for twelve of the fifteen known antimicrobial lasso peptides are deposited in the NCBI database (Table S1). The precursor peptide within each cluster was identified and used as the query for twelve individual BLASTp ${ }^{[47]}$ searches against the NCBI database. All resulting sequences query were selected as initial hits. To verify whether the BLASTp hits were indeed part of lasso peptide BGCs the available genomic sequences (whole genome or BGC) from NCB GenBank for each hit were analyzed by antiSMASH 5.0. ${ }^{[48]} \mathrm{A}$ total of 331 unique BGCs were identified (Dataset 1). The phylogenetic visualization tool CORASON ${ }^{[52]}$ was used to perform multi-locus phylogenetic analyses to understand the evolutionary relationships of lasso peptide BGCs. For this analysis, the lasso cyclase (Protein Accession WP_103143102.1) from the chaxapeptin biosynthetic pathway was selected as the query sequence from the reference cluster of Streptomyces leeuwenhoekii strain C58 (NZ_LFEH01000114). The gbks files collected from antiSMASH for all 331 lasso peptide BGCs were included within the analysis using an Evalue of $10^{-15}$ e-cluster and e-core of $10^{-3}$, rescale value of 85000 , bitscore of 0 , and a cluster ratio of 10 . The phylogenetic tree generated from CORASON was exported using MUSCLE v.3.8.31[65] and visualized using iTOL ${ }^{[66]}$ to generate an unrooted maximum-likelihood tree. To further visualize the lasso peptide BGC landscape, the program BiG-SCAPE ${ }^{[52]}$ was used to generate the sequence similarity network for the 331 lasso peptide BGCs using the gbks files from antiSMASH. The cut-off distance was set at 0.3 , global alignment mode was activated, the singleton parameter was used to visualize nodes that did not contain an edge to the network, and clan-cutoff was employed to deactivate the second layer of cluster to ensure all BGCs were included in the RiPP family analysis. The network generated through BiG-SCAPE was visualized using Cytoscape version 3.7.1.[67]

Media screen for lasso peptide production from Streptomyces sp. NRRL F-5639

A frozen glycerol stock of Streptomyces sp. NRRL F-5639, obtained from the Agricultural Research Service Culture Collection, was used to inoculate ISP II agar plates and incubated at $28^{\circ} \mathrm{C}$ for 5 days. Spores were collected through scraping of the agar plate and used to inoculate $10 \mathrm{~mL}$ seed cultures. Either reported seed media conditions ${ }^{[38,40,54,55]}$ or ISP1 were used for seed cultures. Seed cultures were grown for 5 days at $28^{\circ} \mathrm{C}$ with orbital shaking at $200 \mathrm{rpm}$ then used to inoculate $10 \mathrm{~mL}$ production cultures at $5 \% \mathrm{v} / \mathrm{v}$. Production media included previously reported media conditions for the production of class I lasso peptides as well as media conditions disclosed for Actinomycete metabolite ${ }^{[59]}$ profiling. Production cultures were incubated at $28^{\circ} \mathrm{C}$ with orbital shaking at $200 \mathrm{rpm}$ for 7 days. To screen each condition, after production, cells were collected through centrifugation for $10 \mathrm{~min}$ at $4225 \mathrm{xg}$ at RT. The aqueous supernatant was separated from the cell pellet, and the pellet was resuspended in $\mathrm{MeOH}$ and extracted overnight by stirring the solution at RT. To monitor for lasso peptide production, both the aqueous supernatant and $\mathrm{MeOH}$ extract of cell mass were screened using MALDI-TOF-MS.

Scale-up production, isolation, and purification of arcumycin 
For large-scale production of arcumycin, RAM media conditions were selected. ${ }^{[59]}$ A frozen vegetative stock of Streptomyces sp. NRRL F5639 was prepped by mixing equal volumes of ISP1 seed media with $40 \%$ glycerol followed by flash freezing with liquid nitrogen and storage at $80{ }^{\circ} \mathrm{C}$. The vegetative stock was used to inoculate ISP II agar plates and incubated at $28^{\circ} \mathrm{C}$ for 5 days. Spores were collected and used to inoculate $30 \mathrm{~mL}$ of ISPI seed medium, which was grown for 5 days at $28^{\circ} \mathrm{C}$ with orbital shaking at $200 \mathrm{rpm}$. Seed culture was used to inoculate $500 \mathrm{~mL}$ of RAM production medium at $5 \% \mathrm{v} / \mathrm{v}$. Production media was incubated at $28{ }^{\circ} \mathrm{C}$ with orbital shaking at $250 \mathrm{rpm}$ for 7 days. Cells were collected through centrifugation, resuspended in $\mathrm{MeOH}$ for cell lysis, and extracted by stirring overnight at RT. After extraction, cell debris was collected through centrifugation and $\mathrm{MeOH}$ extracts were dried under reduced pressure to a residue. After resuspension in an $\mathrm{H}_{2} \mathrm{O} / \mathrm{MeCN}$ solution, the crude extract was subjected to RP-HPLC purification using a Jupiter C18, $250 \times 21.2 \mathrm{~mm}$ column with a linear gradient of $10-90 \%$ B over 60 minutes, where mobile phase $A$ was $0.1 \%$ TFA in $\mathrm{H}_{2} \mathrm{O}$ and mobile phase $\mathrm{B}$ was $0.06 \%$ TFA in MeCN. Semi-pure arcumycin was further purified by HPLC using a Vydac $\mathrm{C} 18250 \times 10 \mathrm{~mm}$ column using the same gradient and runtime giving a yield of $570 \mu \mathrm{g}$ of pure arcumycin.

\section{Carboxypeptidase $Y$ digestion of arcumycin}

Analyses were performed using crude $\mathrm{MeOH}$ extracts of arcumycin. For each reaction, $50 \mu \mathrm{L}$ of crude lasso peptide was dried under reduced pressure. The residue was resuspended in $15 \mu \mathrm{L}$ of buffer containing 50 $\mathrm{mM}$ MES (pH 6.7), $1 \mathrm{mM} \mathrm{CaCl}_{2}$, and $50 \mathrm{mM}$ DTT and reduced for $1 \mathrm{~h}$ at room temperature. To alkylate reduced peptide, iodoacetamide $(15 \mathrm{mM}, 5$ $\mu \mathrm{L})$ in $50 \mathrm{mM} \mathrm{MES}$ buffer ( $\mathrm{pH} 6.7$ ) with $1 \mathrm{mM} \mathrm{CaCl}_{2}$ was added and allowed to react for $1 \mathrm{~h}$ at room temperature. Both samples containing intact or reduced/alkylated arcumycin were digested with carboxypeptidase $\mathrm{Y}$ (5 $\mu \mathrm{g}$ ) overnight at RT. Samples were analyzed using RP-HPLC-MS with a $2.6 \mu \mathrm{m}$ EVO-C18, $100 \times 3 \mathrm{~mm}$ column with a gradient of $10-90 \%$ B over 45 minutes, where mobile phase $A$ was 100: $3: 0.3 \mathrm{H}_{2} \mathrm{O} / \mathrm{MeOH} / \mathrm{TFA}$ and mobile phase $B$ was 100: 3:0.3 $\mathrm{MeCN} / \mathrm{H}_{2} \mathrm{O} / \mathrm{TFA}$. ESI-MS was performed in positive ion mode and extracted ion chromatograms (EIC) were collected for the doubly charged peptide species.

\section{ESI-MS/MS based structural determination.}

For ESI-MS/MS, crude reduced/alkylated peptide was dissolved in $70 \%$ aq. MeCN with $0.1 \%$ TFA. The sample was analyzed with a Thermo Exploris 480 mass spectrometer at $2.5 \mu \mathrm{L} / \mathrm{min}$. The sample was run over a $1 \times 10 \mathrm{~mm}$ Water ACQUITY Premier CSH column with a gradient of 3$60 \%$ B over 45 minutes where mobile phase $\mathrm{A}$ was $\mathrm{H}_{2} \mathrm{O}$ and mobile phase $\mathrm{B}$ was $0.1 \%$ TFA in MeCN. Data was collected at $120 \mathrm{~K}$ for full MS scans and $120 \mathrm{~K}$ for MS/MS scans. Arcumycin was analyzed through MS/MS higher-energy C-trap dissociation (HCD) fragmentation for $[\mathrm{M}+2 \mathrm{H}]^{2+}$ charge state using a normalized collision energy of 40 . Spectra data was analyzed using Interactive Peptide Spectral Annotator. ${ }^{[61]}$

\section{MIC assays}

The antimicrobial activity of arcumycin was determined using a broth microdilution assay with ampicillin acting as a positive control. Bacillus subtilis ATCC 6051, Staphylococcus aureus ATCC 25923, Enterococcus faecalis ATCC 29212, Micrococcus luteus ATCC 4698, and Escherichia coli ATCC 25922 were grown at $37^{\circ} \mathrm{C}, 220 \mathrm{rpm}$ in cation adjusted MuellerHinton Broth (MHB), except M. luteus, which was grown at $28{ }^{\circ} \mathrm{C}$. Antimicrobial peptides were dissolved in $\mathrm{MeOH}$ and tested from a range of $0.125-32 \mu \mathrm{g} / \mathrm{mL}$. The bacteria culture was diluted to a concentration of $2 \times 10^{5} \mathrm{CFU} / \mathrm{mL}$ using MHB. Plates were incubated overnight at $37{ }^{\circ} \mathrm{C}$, except $M$. luteus, which was grown at $28^{\circ} \mathrm{C}$, and inspected visually to determine the MIC. Each reported MIC value is the average of two biological replicates.

\section{B. subtilis lial- $\beta$-gal promoter fusion reporter assay}

The ability of arcumycin to induce cell envelope stress was evaluated using the strain 1A980 Bacillus subtilis BSF2470 obtained from the Bacillus Genetic Stock Center. B. subtilis BSF2470 was grown overnight at $37^{\circ} \mathrm{C}$, $220 \mathrm{rpm}$ in Luria Broth (LB) containing erythromycin $(1 \mu \mathrm{g} / \mathrm{mL})$ for bacterial selection. For the reporter assay, the saturated $B$. subtilis BSF2470 culture $(40 \mathrm{uL})$ was plated on freshly prepared LB agar plates supplemented with erythromycin $(1 \mu \mathrm{g} / \mathrm{mL})$ and X-gal $(200 \mu \mathrm{g} / \mathrm{mL})$. Each disk was loaded with either arcumycin $(6.4 \mu \mathrm{g})$, vancomycin $(6.4 \mu \mathrm{g})$, kanamycin $(6.4 \mu \mathrm{g})$, or $\mathrm{MeOH}(20 \mu \mathrm{L})$. Plates were visualized after $22 \mathrm{~h}$ for production of zones of inhibition.

\section{Acknowledgements}

We wish to thank Duke University the generous support of this research and members of the McCafferty lab for thoughtful discussion and critical reading of this manuscript. We also wish to thank Drs. Peter Silinski, Arthur Moseley, and Matt Foster for mass spectrometry assistance.

Keywords: lasso peptides $\cdot$ antimicrobials $\bullet$ bioinformatics $\bullet$ Actinobacteria $\cdot$ natural products

[1] R. I. Aminov, Front. Microbiol. 2010, 1, 134.

[2] Centers for Disease Control and Prevention., 2019

[3] O. Genilloud, Nat. Prod. Rep. 2017, 34, 1203-1232.

[4] M. H. Medema, M. A. Fischbach, Nat. Chem. Biol. 2015, 11, 639648.

[5] P. G. Arnison, M. J. Bibb, G. Bierbaum, A. A. Bowers, T. S. Bugni, G. Bulaj, J. A. Camarero, D. J. Campopiano, G. L. Challis, J. Clardy, P. D. Cotter, D. J. Craik, M. Dawson, E. Dittmann, S. Donadio, P. C Dorrestein, K. D. Entian, M. A. Fischbach, J. S. Garavelli, U. Göransson, C. W. Gruber, D. H. Haft, T. K. Hemscheidt, C. Hertweck, C. Hill, A. R. Horswill, M. Jaspars, W. L. Kelly, J. P. Klinman, O. P. Kuipers, A. J. Link, W. Liu, M. A. Marahiel, D. A. Mitchell, G. N. Moll, B. S. Moore, R. Müller, S. K. Nair, I. F. Nes, G. E. Norris, B. M. Olivera, H. Onaka, M. L. Patchett, J. Piel, M. J. T. Reaney, S. Rebuffat, R. P. Ross, H. G. Sahl, E. W. Schmidt, M. E. Selsted, K. Severinov, B. Shen, K. Sivonen, L. Smith, T. Stein, R. D. Süssmuth, J. R. Tagg, G. L. Tang, A. W. Truman, J. C. Vederas, C. T. Walsh, J. D. Walton, S. C. Wenzel, J. M. Willey, W. A. Van Der Donk, Nat. Prod. Rep. 2013, 30, 108-160.

[6] W. L. Cheung-Lee, A. J. Link, J. Ind. Microbiol. Biotechnol. 2019, 46, 1371-1379.

[7] M. Tsunakwa, S.-L. Hu, Y. Hoshino, D. J. Detlefson, S. E. Hill, T. Furumai, R. J. White, K. Kawano, S. Yamamoto, Y. Fukagawa, T. Oki, J. Antibiot. (Tokyo). 1995, 48, 433-434.

[8] H. Nakashima, K. Ichiyama, K. Inazawa, M. Ito, H. Hayashi, Y. Nishihara, E. Tshuhii, T. Kino, Biol. Pharm. Bull. 1996, 19, 405-412.

[9] S. Son, M. Jang, B. Lee, Y. S. Hong, S. K. Ko, J. H. Jang, J. S. Ahn, J. Nat. Prod. 2018, 81, 2205-2211.

[10] T. A. Knappe, F. Manzenrieder, C. Mas-Moruno, U. Linne, F. Sasse, H. Kessler, X. Xie, M. A. Marahiel, Angew. Chemie Int. Ed. 2011, 50, 8714-8717.

[11] T. A. Knappe, U. Linne, S. Zirah, S. Rebuffat, X. Xie, M. A. Marahiel, J. Am. Chem. Soc. 2008, 130, 11446-11454.

[12] M. O. Maksimov, I. Pelczer, A. J. Link, Proc. Natl. Acad. Sci. U. S A. 2012, 109, 15223-15228.

[13] M. Metelev, A. Arseniev, L. B. Bushin, K. Kuznedelov, T. O. Artamonova, R. Kondratenko, M. Khodorkovskii, M. R. Seyedsayamdost, K. Severinov, ACS Chem. Biol. 2017, 12, 814824.

[14] S. Tan, G. Moore, J. Nodwell, Antibiotics 2019, 8, 117.

[15] P. Zhao, Y. Xue, W. Gao, J. Li, X. Zu, D. Fu, S. Feng, X. Bai, Y. Zuo, P. Li, Peptides 2018, 103, 48-59.

[16] M. O. Maksimov, S. J. Pan, A. J. Link, Nat. Prod. Rep. 2012, 29, 996-1006.

[17] R. Ducasse, K.-P. Yan, C. Goulard, A. Blond, Y. Li, E. Lescop, E. Guittet, S. Rebuffat, S. Zirah, ChemBioChem 2012, 13, 371-380. J. D. Hegemann, ChemBioChem 2020, 21, 7-18.

[19] M. Zimmermann, J. D. Hegemann, X. Xie, M. A. Marahiel, Chem. 
Biol. 2013, 20, 558-569.

[20]

H. Martin-Gómez, J. Tulla-Puche, Org. Biomol. Chem. 2018, 16 5065.

[21] W. L. Cheung-Lee, M. E. Parry, A. J. Cartagena, S. A. Darst, A. J. Link, J. Biol. Chem. 2019, 294, 6822-6830.

[22] J. D. Hegemann, C. J. Schwalen, D. A. Mitchell, W. A. Van der Donk, Chem. Commun. 2018, 54, 9007-9010.

[23] W. L. Cheung-Lee, M. E. Parry, C. Zong, A. J. Cartagena, S. A. Darst, N. D. Connell, R. Russo, A. J. Link, ChemBioChem 2020, 21 , 1335-1340.

[24] S. Um, Y. J. Kim, H. Kwon, H. Wen, S. H. Kim, H. C. Kwon, S. Park, J. Shin, D. C. Oh, J. Nat. Prod. 2013, 76, 873-879.

[25] C. Cortés-Albayay, S. A. Jarmusch, F. Trusch, R. Ebel, B. A. Andrews, M. Jaspars, J. A. Asenjo, J. Org. Chem. 2020, 85, 16611667.

[26] E. Gavrish, C. S. Sit, S. Cao, O. Kandror, A. Spoering, A. Peoples, L. Ling, A. Fetterman, D. Hughes, A. Bissell, H. Torrey, T. Akopian, A. Mueller, S. Epstein, A. Goldberg, J. Clardy, K. Lewis, Chem. Biol. 2014, 21, 509-518.

[27] F. Xu, Y. Wu, C. Zhang, K. M. Davis, K. Moon, L. B. Bushin, M. R. Seyedsayamdost, Nat. Chem. Biol. 2019, 15, 161-168.

[28] J. P. Gomez-Escribano, J. F. Castro, V. Razmilic, S. A. Jarmusch, G. Saalbach, R. Ebel, M. Jaspars, B. Andrews, J. A. Asenjo, M. J. Bibb, Appl. Environ. Microbiol. 2019, 85.

[29] M. A. Skinnider, C. W. Johnston, R. E. Edgar, C. A. Dejong, N. J. Merwin, P. N. Rees, N. A. Magarvey, Proc. Natl. Acad. Sci. U. S. A. 2016, 113, E6343-E6351.

[30] M. O. Maksimov, A. J. Link, J Ind Microbiol Biotechnol 2014, 41, 333-344.

[31] J. I. Tietz, C. J. Schwalen, P. S. Patel, T. Maxson, P. M. Blair, H.-C. Tai, U. I. Zakai, D. A. Mitchell, Nat. Chem. Biol. 2017, 13, 470-478.

[32] A. M. Kloosterman, P. Cimermancic, S. S. Elsayed, C. Du, M. Hadjithomas, M. S. Donia, M. A. Fischbach, G. P. van Wezel, M. H. Medema, PLOS Biol. 2020, 18, e3001026.

[33] E. V. Bratovanov, K. Ishida, B. Heinze, S. J. Pidot, T. P. Stinear, J. D. Hegemann, M. A. Marahiel, C. Hertweck, ACS Chem. Biol. 2020, 15, 1169-1176.

[34] C. Zong, W. L. Cheung-Lee, H. E. Elashal, M. Raj, A. J. Link, Chem. Commun. 2018, 54, 1339-1342.

[35] S. Kodani, K. Unno, J. Ind. Microbiol. Biotechnol. 2020, 47, 703714.

[36] S. S. Elsayed, F. Trusch, H. Deng, A. Raab, I. Prokes, K. Busarakam, J. A. Asenjo, B. A. Andrews, P. Van West, A. T. Bull, M. Goodfellow, Y. Yi, R. Ebel, M. Jaspars, M. E. Rateb, J. Org. Chem. 2015, 80, 10252-10260.

[37] N. Takasaka, I. Kaweewan, M. Ohnishi-Kameyama, S. Kodani, Lett. Appl. Microbiol. 2017, 64, 150-157.

[38] Y. Li, R. Ducasse, S. Zirah, A. Blond, C. Goulard, E. Lescop, C. Giraud, A. Hartke, E. Guittet, J. L. Pernodet, S. Rebuffat, ACS Chem. Biol. 2015, 10, 2641-2649.

[39] I. Kaweewan, M. Ohnishi-Kameyama, S. Kodani, J. Antibiot. (Tokyo). 2017, 70, 208-211.

[40] I. Kaweewan, H. Hemmi, H. Komaki, S. Harada, S. Kodani, Bioorganic Med. Chem. 2018, 26, 6050-6055.

[41] M. Iwatsuki, H. Tomoda, R. Uchida, H. Gouda, S. Hirono, S. Omura, J. Am. Chem. Soc. 2006, 128, 7486-7491.

[42] Y. Esumi, Y. Suzuki, Y. Itoh, M. Uramoto, K. I. Kimura, M. Goto, M. Yoshihama, T. Ichikawa, J. Antibiot. (Tokyo). 2002, 55, 296-300.
[43] T. Zyubko, M. Serebryakova, J. Andreeva, M. Metelev, G. Lippens, S. Dubiley, K. Severinov, Chem. Sci. 2019, 10, 9699-9707.

[44] S. Kodani, Y. Inoue, M. Suzuki, H. Dohra, T. Suzuki, H. Hemmi, M. Ohnishi-Kameyama, European J. Org. Chem. 2017, 2017, 11771183.

[45] S. Zhu, C. D. Fage, J. D. Hegemann, A. Mielcarek, D. Yan, U. Linne, M. A. Marahiel, Sci. Rep. 2016, 6, 1-12.

[46] C. Cheng, Z. C. Hua, Front. Bioeng. Biotechnol. 2020, 8, 1131. [47] NCBI Resource Coordinators, Nucleic Acids Res. 2015, 43, D6-17. [48] K. Blin, S. Shaw, K. Steinke, R. Villebro, N. Ziemert, S. Y. Lee, M. H. Medema, T. Weber, Nucleic Acids Res. 2019, 47, W81-W86.

[49] Y. Morishita, S. Chiba, E. Tsukuda, T. Tanaka, T. Ogawa, M. Yamasaki, M. Yoshida, Y. Matsuda, I. Kawamoto, J. Antibiot. (Tokyo). 1994, 47, 269-275.

[50] V. Valiante, M. C. Monteiro, J. Martín, R. Altwasser, N. El Aouad, I. González, O. Kniemeyer, E. Mellado, S. Palomo, N. De Pedro, I. Pérez-Victoria, J. R. Tormo, F. Vicente, F. Reyes, O. Genilloud, A. A. Brakhage, Antimicrob. Agents Chemother. 2015, 59, 5145-5153.

[51] S. Sugai, M. Ohnishi-Kameyama, S. Kodani, Appl. Biol. Chem. 2017, 60, 163-167.

[52] J. C. Navarro-Muñoz, N. Selem-Mojica, M. W. Mullowney, S. A. Kautsar, J. H. Tryon, E. I. Parkinson, E. L. C. De Los Santos, M. Yeong, P. Cruz-Morales, S. Abubucker, A. Roeters, W. Lokhorst, A. Fernandez-Guerra, L. T. D. Cappelini, A. W. Goering, R. J. Thomson, W. W. Metcalf, N. L. Kelleher, F. Barona-Gomez, M. H. Medema, Nat. Chem. Biol. 2020, 16, 60-68.

[53] S. Tan, K. C. Ludwig, A. Mü, T. Schneider, J. R. Nodwell, ACS Chem. Biol 2019, 14, 31.

[54] T. Yamamoto, H. Matsui, K. Yamaji, T. Takahashi, A. Øverby, M. Nakamura, A. Matsumoto, K. Nonaka, T. Sunazuka, S. Ōmura, H. Nakano, J. Infect. Chemother. 2016, 22, 587-592.

[55] J. Nakayama, E. Tanaka, R. Kariyama, K. Nagata, K. Nishiguchi, R. Mitsuhata, Y. Uemura, M. Tanokura, H. Kumon, K. Sonomoto, J. Bacteriol. 2007, 189, 1358-1365.

[56] S. Duquesne, D. Destoumieux-Garzón, S. Zirah, C. Goulard, J. Peduzzi, S. Rebuffat, Chem. Biol. 2007, 14, 793-803.

[57] Z. Feng, Y. Ogasawara, S. Nomura, T. Dairi, ChemBioChem 2018, 19, 2045-2048.

[58] M. Shao, J. Ma, Q. Li, J. Ju, Mar. Drugs 2019, 17, 127.

[59] J. R. Tormo, J. B. García, M. DeAntonio, J. Feliz, A. Mira, M. T. Díez, P. Hernández, F. Peláez, J. Ind. Microbiol. Biotechnol. 2003, 30, 582-588.

[60] S. A. Jarmusch, I. Feldmann, B. Blank-Landeshammer, C. CortésAlbayay, J. F. Castro, B. Andrews, J. A. Asenjo, A. Sickmann, R. Ebel, M. Jaspars, J. Antibiot. (Tokyo). 2020, 73, 772-779.

[61] D. R. Brademan, N. M. Riley, N. W. Kwiecien, J. J. Coon, Mol. Cell. Proteomics 2019, 18, S193-S201.

[62] M. O. Maksimov, A. J. Link, J. Am. Chem. Soc. 2013, 135, 1203812047.

[63] M. Metelev, J. I. Tietz, J. O. Melby, P. M. Blair, L. Zhu, I. Livnat, K. Severinov, D. A. Mitchell, Chem. Biol. 2015, 22, 241-250.

[64] T. Mascher, S. L. Zimmer, T. A. Smith, J. D. Helmann, Antimicrob. Agents Chemother. 2004, 48, 2888-2896.

[65] F. Madeira, Y. mi Park, J. Lee, N. Buso, T. Gur, N. Madhusoodanan, P. Basutkar, A. R. N. Tivey, S. C. Potter, R. D. Finn, R. Lopez, F. Madeira, Y. mi Park, J. Lee, N. Buso, T. Gur, N. Madhusoodanan, R. Lopez, Nucleic Acids Res. 2019, 47I, W636W641. 
[66] I. Letunic, P. Bork, Nucleic Acids Res. 2019, 47, W256-W259.

[67] P. Shannon, A. Markiel, O. Ozier, N. S. Baliga, J. T. Wang, D.

Ramage, N. Amin, B. Schwikowski, T. Ideker, Genome Res. 2003,

13, 2498-2504. 
